\title{
Chronic intestinal pseudo-obstruction: treatment and long term follow up of 44 patients
}

\author{
S Heneyke, V V Smith, L Spitz, P J Milla
}

\begin{abstract}
Aims-To document the long term course of chronic idiopathic intestinal pseudoobstruction syndrome (CIIPS) in children with defined enteric neuromuscular disease, and the place and type of surgery used in their management; in addition, to identify prognostic factors.

Methods-Children with CIIPS were investigated and treated prospectively.

Results-Twenty four children presented congenitally, eight during the 1st year of life, and 10 later. Twenty two had myopathy and 16 neuropathy (11 familial). Malrotation was present in 16 patients, 10 had short small intestine, six had nonhypertrophic pyloric stenosis, and 16 had urinary tract involvement. Thirty two patients needed long term parenteral nutrition (TPN): for less than six months in 19 and for more than six months in 13, 10 of whom are TPN dependent; 14 are now enteral feeding. Prokinetic treatment improved six of 22 . Intestinal decompression stomas were used in 36 , colostomy relieved symptoms in five of 11 , and ileostomy in 16 of 31 . A poor outcome (death (14) or TPN dependence (10)) was seen with malrotation (13 of 16), short small bowel (eight of nine), urinary tract involvement (12 of 16), and myopathic histology (15 of 22).

Conclusions-In CIIPS drugs are not helpful but decompression stomas are. Outcome was poor in 24 of 44 children ( 15 muscle disorder, 10 nerve disease). (Arch Dis Child 1999;81:21-27)
\end{abstract}

Keywords: chronic intestinal pseudo-obstruction; decompression stomas; prognostic factors; total parenteral nutrition

Institute of Child

Health and Great

Ormond Street

Hospital for Children

NHS Trust, London,

UK

$S$ Heneyke

V V Smith

L Spitz

P J Milla

Correspondence to:

Dr P J Milla,

Gastroenterology Unit,

Institute of Child Health,

30 Guilford Street, London

WC1N 1EH, UK

email:P.Milla@ich.ucl.ac.uk

Accepted 22 December 1998

Chronic idiopathic intestinal pseudoobstruction syndrome (CIIPS) is an intestinal motility disorder in which impaired intestinal motor activity causes recurrent symptoms of intestinal obstruction in the absence of mechanical occlusion. It is usually caused by disease of the enteric neuromusculature and may involve either segments of, or the entire, gastrointestinal tract. It is an uncommon disorder with a high morbidity and mortality. Until the last 10 years few patients survived long enough for the natural history of CIIPS to be apparent, and the place of surgery in its management is still not well defined. ${ }^{1-8}$ The aims of our study were to document the course of the disorder in a large number of patients, in whom the underlying enteric neuromuscular disease had been clarified, from one centre over a long period of time, to determine the place and type of surgery used in their management, and to identify prognostic factors.

The histopathological features and motility abnormalities have been reported previously and will not be considered in detail here.

\section{Methods}

Between 1979 and 1997, 44 children with recurrent symptoms of bowel obstruction in the absence of a mechanical occlusion, in whom Hirschsprung's disease was excluded, were investigated prospectively to define the cause and extent of the bowel disorder.

We noted the age at onset of illness, the presenting symptoms, drugs given, specific nutritional support used, and the types of surgery performed. We performed marker transit studies, abdominal ultrasound, and contrast $x$ ray studies in all children; upper gastrointestinal contrast studies in 32 children, and contrast studies of the lower gastrointestinal tract in 22 . If there was involvement of the urinary tract, the extent of involvement, the management, and the outcome were noted.

\section{HISTOPATHOLOGY}

Full thickness intestinal biopsies were available from 44 patients, but for two patients the material was obtained postmortem. These comprised both small and large intestine from 22 patients, small bowel alone from 17, and large bowel alone from five. We performed routine histology, enzyme histochemistry, and immunocytochemistry by light microscopy and ultrastructural studies by electron microscopy as described previously (VV Smith, PhD thesis, University of London, 1993)..$^{10-12}$

\section{MOTILITY STUDIES}

Surface electrogastrography

We recorded fasting gastric electrical control activity (ECA) in 16 patients who initially presented after 1989 and the results were analysed using our previously described method. ${ }^{6}$ In summary, four pairs of $\mathrm{Ag}-\mathrm{AgCl}$ electrodes matched for impedance were placed along the greater curvature of the stomach from the fundus to the first part of the duodenum and the potential differences across these pairs of electrodes were measured for one hour after a four hour fast or during small intestinal manometry. The frequencies present were determined by autoregressive modelling using a running spectral analysis method. ${ }^{6}$ After running spectral analysis of gastric ECA the dominant frequency was determined if present. 
Table 1 Clinical details of 44 patients with chronic intestinal pseudo-obstruction

\begin{tabular}{|c|c|c|c|c|c|c|c|c|}
\hline \multirow[b]{3}{*}{ Patients } & \multicolumn{5}{|c|}{ Presentation } & \multirow[b]{3}{*}{ Histology } & \multirow[b]{3}{*}{ Surgery } & \multirow[b]{3}{*}{ Outcome } \\
\hline & Weight ce & & & & & & & \\
\hline & Birth & Present & Age & Symptoms & Radiology & & & \\
\hline \multirow[t]{2}{*}{$1-6$} & 3 rd to & - & Birth & Vomiting & Dilated whole gut & $5 \mathrm{M}$ & 6 Ladd's procedure & 4 dead \\
\hline & 50 th & & & Intestinal obstruction & $\begin{array}{l}\text { Pyloric obstruction } \\
\text { Short small intestine } \\
\text { Malrotation }\end{array}$ & $1 \mathrm{~N}$ & $\begin{array}{l}6 \text { ileostomy } \\
6 \text { pyloromyotomy }\end{array}$ & 2 TPN \\
\hline \multirow[t]{3}{*}{$7-13$} & 3 rd to & - & Antenatal & Vomiting & Dilated bowel & M & Ileostomy & 4 dead \\
\hline & 25 th & & & Failure to pass urine & Megacystis & & & 1 enteral \\
\hline & & & & Intestinal obstruction & $\begin{array}{l}\text { Megaureter } \\
3 \text { malrotation }\end{array}$ & & & $2 \mathrm{TPN}$ \\
\hline \multirow[t]{3}{*}{$14-24$} & $3 \mathrm{rd}$ to & $<3$ rd to & Birth to 7 & Constipation & Megacystis & $9 \mathrm{M}$ & Ileostomy & 3 dead \\
\hline & 50th & 10th & years & Obstruction & Megaureter & $2 ?$ & & 6 enteral \\
\hline & & & & Abdominal distension & $\begin{array}{l}1 \text { hydronephrosis } \\
\text { Dilated bowel }\end{array}$ & & & $2 \mathrm{TPN}$ \\
\hline \multirow[t]{2}{*}{$25-30$} & 10th to & 3 rd to & Birth to 2 & Constipation & Slow transit & $6 \mathrm{~N}$ & 3 colostomy & 2 gastrostomy \\
\hline & 75th & 25 th & years & $\begin{array}{l}\text { Dilated bowel } \\
1 \text { stricture }\end{array}$ & & & & 4 normal feeds \\
\hline \multirow[t]{3}{*}{$31-42$} & 3 rd to & $<3$ rd to & Birth to 3 & Constipation & 10 contracted colon & $8 \mathrm{~N}$ & 2 colostomy & 3 dead \\
\hline & 50th & 10th & years & Obstruction & 3 malrotation & $4 ?$ & 5 ileostomy & 7 enteral \\
\hline & & & & Abdominal distension & 4 short small intestine & & & $2 \mathrm{TPN}$ \\
\hline 43 & 10th & $<3$ rd & 2 years & Obstruction & Dilated bowel & $\mathrm{M}$ & Ileostomy & TPN \\
\hline 44 & 25 th & $<3$ rd & 10 years & $\begin{array}{l}\text { Severe constipation } \\
\text { Abdominal distension }\end{array}$ & Dilated bowel & $\mathrm{N}$ & Ileostomy & TPN \\
\hline
\end{tabular}

Present, presentation; M, myopathy; N, neuropathy; ?, unknown; TPN, long term total parenteral nutrition.

\section{Small intestinal manometry}

We assessed motor activity in the duodenum manometrically in 30 patients investigated since 1981 after an overnight 15 hour fast as described previously. ${ }^{13}$ We recorded fasting motor activity for three interdigestive cycles, where this was present, or for four hours, whichever was longer. The manometric patterns were analysed by means of visual planimetry by two blinded independent observers. ${ }^{13}$ Because the infants were vomiting and had a severe intolerance to feeds, postprandial activity was not studied.

\section{STATISTICS}

Fisher's exact probability test was applied to determine whether there were any significant prognostic factors.

\section{Results}

The criteria for the diagnosis of CIIPS were fulfilled by 44 patients ( 25 boys, 19 girls). Histopathology was available in all and motility, contrast, and marker transit studies in most. Thirty of the 44 patients had survived at the time of our study and had a mean age of 12 years (range, 3 months to 26 years). Details of all 44 patients are summarised in table 1.

\section{ONSET OF SYMPTOMS AND CLINICAL}

PRESENTATION

Twenty four children developed obstructive symptoms during the 1 st month of life: 18 were symptomatic at birth and seven were evident on ultrasound scanning antenatally. A further eight developed symptoms during the 1 st year of life and 10 before the $3 \mathrm{rd}$ year of life. Two children did not develop constipation or obstructive symptoms until the age of 6 and 10 years, respectively. Seven had evidence of active disease in utero with an obstructed urinary system on antenatal ultrasound.

ULTRASOUND AND RADIOLOGICAL INVESTIGATION All patients had a whole gut transit time of $>96$ hours. Key radiological features are shown in table 1 . Ten neonates presented with abdominal distension and bilious vomiting and an abdominal $x$ ray suggestive of distal bowel obstruction. Seven neonates presented with the diagnosis of an obstructed urinary system on antenatal ultrasound scanning and failure to pass urine. Symptoms of intestinal obstruction developed during the 1 st month of life in six and by the 4 th month of life in two other infants. Five neonates, presenting with bilious vomiting and a paucity of intestinal gas on abdominal $x$ ray, had a midgut malrotation on contrast study. One child presented with a gastroschisis and one with a ruptured exomphalos, both had persistent abdominal distension and bilious vomiting during the postoperative period. After the 1st month of life, the most common mode of presentation was chronic constipation and abdominal distension with episodic vomiting. In three of the older children a febrile illness preceded the onset of gastrointestinal symptoms by a few days. Barium meal and follow through revealed a midgut malrotation in 16 , a short small intestine in nine, and a non-hypertrophic pyloric stenosis in six. Six of these presented as neonates and had a midgut malrotation, short small intestine, and a non-hypertrophic plyoric stenosis. In four patients, three from one family, circular muscle morphogenesis was abnormal, with two circular muscle coats. In general, a barium enema was not helpful but suggested pseudo-Hirschsprung's disease with a contracted left sided segment in 11 patients, nine of whom had nerve disease.

In those with an obstructed urinary system prenatally $(n=7)$, urinary tract infections were common. But in nine of 44, urinary tract anomalies were found on routine investigation without initial obstructive or infective symptoms. All of these had muscle disease.

FAMILY HISTORY

There were 11 cases in six families. In one family all three children were affected (female twins and their brother), in another two sisters, and in two families a brother and sister were 
Table 2 Primary surgical procedures and outcome

\begin{tabular}{lll}
\hline Surgical procedure & $\begin{array}{l}\text { Number of } \\
\text { patients }\end{array}$ & $\begin{array}{l}\text { Number with relief of } \\
\text { symptoms }\end{array}$ \\
\hline Ladd's procedure & 10 & 0 \\
Pyloromyotomy/excision & 5 & 0 \\
Gastro-jejunostomy & 2 & 0 \\
Colostomy & 11 & 5 \\
Ileostomy & 31 & 16 (10 total, 6 partial)
\end{tabular}

affected, suggesting an autosomal mode of inheritance. In the two remaining families (one with myopathic, the other with neuropathic disease) the inheritance appeared to be $\mathrm{X}$-linked. We have shown previously that the latter condition maps to chromosome Xq28. ${ }^{14}$

ASSOCIATED ANOMALIES

There was a high incidence of associated anomalies, 16 of the patients had a midgut malrotation, 10 of whom had a shorter than normal small bowel. The urinary tract was involved in 16 of the patients.

\section{HISTOPATHOLOGY}

Histopathological evidence of enteric neuromuscular disease ${ }^{10121516}$ was seen in 38 of the 44 patients. Enteric muscle disease was seen in 22 , including four patients with an additional smooth muscle coat. Intestinal neuropathy was present in 16 .

\section{MOTILITY STUDIES}

Manometry was performed in 30 children. A myopathic trace was present in 13 and a neuropathic trace in 14 patients. In three children no contractile activity was seen. These three all had myopathic disease. The small intestinal manometry correlated well with the final histology.

Electrogastrography was carried out in 16 patients. In 10 of these patients, no dominant frequency could be found, which is suggestive of muscle disease; in five a tachygastria indicating a neuropathic process was found; and in one patient a normal dominant frequency of $0.048 \mathrm{~Hz}$ was present.

\section{MEDICATION}

Carbachol, bethanechol, propranolol, and metoclopramide were used up until 1984 with no consistent success. From 1984 cisapride was used in doses of $0.2-0.3 \mathrm{mg} / \mathrm{kg}$ body weight three times daily; this produced a temporary improvement in symptoms in six of 22 patients. Bacterial overgrowth was treated according to antibiotic sensitivity. Colistin, cotrimoxazole, and metronidazole were the most common antibiotics used for treating intestinal bacterial overgrowth. Antibiotics

Table 3 Definitive surgical procedures

\begin{tabular}{lll}
\hline Procedure & $\begin{array}{l}\text { Number of } \\
\text { patients }\end{array}$ & Outcome \\
\hline Colostomy closure & 4 & Constipation \\
Colorectal pull through & 1 & Constipation and soiling \\
Colorectal pull through & 2 & Needed ileo-rectal pull through \\
Ileocolic anastomosis & 3 & Needed ileo-rectal pull through \\
Ileorectal pull through & 6 & Very good \\
Ileoanal anastomosis & 1 & Very good \\
\hline
\end{tabular}

were helpful in reducing stool output and abdominal distension but only for short periods of time.

\section{SURGICAL MANAGEMENT}

The diagnosis of CIIPS was not considered at the initial laparotomy in 28 of 44 patients. In 10 patients, CIIPS was diagnosed on clinical history and on the results of investigations without resorting to surgery. Table 2 shows the outcome of the initial surgical procedures. There was no significant relief of symptoms following Ladd's procedure, pyloromyotomy, pyloric excision, or gastro-jejunostomy. Colostomy effectively relieved symptoms in five of 11 patients, whereas in the remaining six patients the colostomy had to be converted to ileostomy because the obstructive symptoms persisted. A total of 31 patients had an ileostomy, with symptomatic relief in 16 .

Stomal complications were common. Half of the children had an irregular ileostomy output alternating between low output with abdominal distension and vomiting followed by massive ileostomy losses resulting in fluid and electrolyte imbalance.

Eight children had a total of 17 ileostomy revision procedures, eight for prolapse of stoma and nine for suspected mechanical occlusion. Multiple adhesions were found at each operation but there were no correctable focal mechanical obstructing lesions and there was no noticeable change in ileostomy function after the revisional surgery. Four patients had their ileostomies closed when they were asymptomatic but all four needed replacement ileostomy as they rapidly developed acute obstructive symptoms.

Reconstitution of continuity of the gastrointestinal tract was carried out in seven patients after initial stoma formation, four with closure of colostomy and three by ileo-colic anastomosis. None of these procedures was successful. The three in whom an ileo-colic anastomosis was done required an ileo-rectal Duhamel pull through to relieve obstructive symptoms. Six children had an ileo-rectal Duhamel pull through with good outcome. The results of the various operative procedures are shown in table 3

\section{NUTRITIONAL SUPPORT}

Thirty two patients required long term parenteral nutrition (TPN); 19 for less than six months, 11 of whom died. Thirteen needed TPN for longer than six months, 10 of these are still TPN dependent (for up to 16 years), and three are dead. Only eight patients have successfully been weaned off TPN, all of whom needed TPN for short periods only, with the maximum duration of less than six months.

\section{OUTCOME}

The outcome was defined as good when the child was alive and enterally fed and poor if the child had either died or was dependent on TPN. Of the 44 patients, 20 are alive and enterally fed and thus have a good outcome. However 14 have died and an additional 10 experience recurrent episodes of pseudo- 
Table 4 Prognostic factors

\begin{tabular}{llll}
\hline & Total & $\begin{array}{l}\text { Good } \\
\text { outcome }\end{array}$ & $\begin{array}{l}\text { Poor } \\
\text { outcome }\end{array}$ \\
\hline Malrotation & 16 & 3 & 13 \\
Short small bowel & 9 & 1 & 8 \\
Urinary involvement & 16 & 4 & 12 \\
Muscle disease & 22 & 7 & 15 \\
\hline
\end{tabular}

$\mathrm{p}<0.05$ for all prognostic factors.

obstruction and are dependent on TPN. Therefore, these 24 patients had a poor outcome. Of the infants who died, three died as a result of withholding or withdrawing active treatment, nine died secondary to TPN related complications, and two died postoperatively after a laparotomy at other hospitals.

Fisher's exact probability test was applied to a number of factors to determine which had a significant influence on the outcome. These factors and their significance are shown in table 4. The presence of midgut malrotation, short small intestine, involvement of the urinary system, $<1$ year of age at onset, and myopathy on histology were significantly $(p<0.05)$ poor prognostic factors. The sex of the child and a neuropathic histology were not significant features, with the exception of one child with acquired autoimmune aganglionosis who presented at the age of 10 years. ${ }^{15}$

\section{Discussion}

CIIPS in children has been reported under a variety of names; megacystis-microcolonintestinal hypoperistalsis syndrome, intestinal pseudo-obstruction, chronic adynamic ileus, pseudo-Hirschsprung's disease, adynamic bowel syndrome, colonic neuronal dysplasia, and hollow visceral myopathy. ${ }^{17-25}$ It is the result of a heterogeneous group of disorders of the enteric neuromusculature that cause severe intestinal dysmotility, resulting in functional obstruction. ${ }^{26-30}$

Analysis of published studies has shown that most patients develop symptoms early in life. ${ }^{31}$ In this series, 32 of 44 children developed symptoms during the 1 st year of life. At birth they may present with obstruction of either the gut or urinary tract, or both. A persistent bilious aspirate can indicate an associated midgut malrotation. Later, the main presentation is with chronic constipation and/or abdominal distension associated with obstruction and episodic vomiting, which may be bile stained. Previous studies have either been of small numbers of patients or have been multicentred with poorly validated data.

The diagnosis of CIIPS is dependent on the awareness of the clinician, the recognition of the clinical syndrome, and the exclusion of mechanical obstruction by radiological assessment and exclusion of Hirschsprung's disease by rectal biopsy. The patient often undergoes exploratory laparotomy before the diagnosis is considered. The main diagnostic difficulties are the poor specificity of clinical features and the absence of established diagnostic tests. ${ }^{19} 32$ CIIPS should be considered as a probable diagnosis when there are continuing symptoms after Ladd's procedure for midgut malrotation, when intestinal obstruction is associated with bladder dysmotility, or when in early life there is recurrent obstruction after exclusion of Hirschsprung's disease by rectal biopsy. In our hands, surface electrogastrography has proved to be a useful screening investigation followed by upper gastrointestinal contrast study. Dilated small bowel with impaired or retrograde peristalsis and stasis of contrast are suggestive of small bowel dysmotility, ${ }^{33}$ which requires confirmation by antroduodenal manometry. In addition, it may differentiate between a myopathic process and a neuropathic process. ${ }^{34} 35$ The aim should be to avoid an exploratory laparotomy but to have planned surgery if there is a need for a defunctioning ileostomy to decompress the intestine. At this time, it is mandatory that full thickness tissue is obtained to determine the type of enteric neuromuscular disease. Our data indicate that this has prognostic value, with muscle disease having a poorer outcome than nerve disease, and the presence of muscle disease may indicate a congenital disorder. Because of the subtle nature of abnormalities in enteric nerves and muscle in CIIPS, routine microscopy alone is generally unhelpful in making the diagnosis. The use of electron microscopy and histochemical (enzyme and immunohistochemisty) techniques allows the detection of a wider range of changes, thus enabling a more accurate histological classification of the patients into myopathic and neuropathic groups, ${ }^{12}$ which is relevant in predicting the clinical outcome. Therefore, it is important to preserve the resected full thickness sample in ways that permit ultrastructural examination (glutaraldehyde fixation), immunohistochemistry, and enzyme histochemistry (snap freezing), in addition to routine light microscopy (VV Smith, $\mathrm{PhD}$ thesis). (Although silver staining was used in the early patients (17 of 44 ) in our series, it must be born in mind that it is unreliable in young babies because argyrophilic neurons are present constantly only in children older than 1 year, ${ }^{36}$ and we feel that this method is no longer of value in the paediatric population.)

The initial objectives of treatment must be to rehydrate and restore the normal electrolyte and acid/base balance, to control obstructive symptoms, and to control urinary and enteric bacterial overgrowth. This will require medical, surgical, and nutritional management. Each has a part to play and must be used in the correct manner for optimal treatment.

Carbachol, bethanocol, propranalol, metoclopramide, erythromycin, and neostigmine have all been used to restore the disturbed gastrointestinal motility in patients with CIIPS, but with only limited success. ${ }^{37-40}$ Cisapride has been shown to be the most effective prokinetic agent. ${ }^{41-43}$ In our series, cisapride achieved only temporary relief of symptoms in about a quarter of patients and the symptoms returned within a few months in all.

Treatment of bacterial overgrowth with broad spectrum antibiotics was difficult, and was only successful when microbiology isolated the important dominating organisms of the intestinal flora. Urinary infections were con- 
trolled using standard treatments for recurrent infections.

Until now, the place of surgery in the management of CIIPS has been ill defined. However, our study clearly shows that pyloromyotomy, excision of the pylorus, and gastrojejunostomy are of no benefit in relieving symptoms because the apparent gastric outlet obstruction seen in this disorder is secondary to dysmotility of the stomach and intestine. ${ }^{1}$ Ladd's procedure for malrotation was similarly unsuccessful in relieving the obstructive symptoms of the underlying enteric neuromuscular disease, but did prevent volvulus from occurring.

Dramatic symptom relief can be expected with a defunctioning stoma if the pathology is confined to the bowel distal to the stoma. In our series a defunctioning stoma relieved symptoms completely in a quarter of the patients in whom the disorder was confined to the terminal ileum and colon. It was partially successful in a quarter and was ineffectual in half of patients in whom the gut was diffusely affected along its entire length. Vargas et al reported the results of a large survey in North America conducted in 1988 in which patients were reported by questionnaire. ${ }^{44}$ Exact numbers of patients who underwent surgery were not given but they felt that in many of the patients diversion through defunctioning stomas was done with temporary, partial, or no relief of obstruction. ${ }^{44}$ Another recent review of children who had defunctioning stomas showed no relief of symptoms. ${ }^{45}$ However, like our present study other reports do show benefit from defunctioning or decompression stomas. ${ }^{4647}$ Similarly, the effectiveness of a stoma in reducing gaseous distension and bloating in patients on parenteral nutrition has been reported previously. ${ }^{48}{ }^{49}$ It is advantageous to decompress the small bowel early in the course of the illness, before gross dilatation occurs, because this itself reduces effective motor activity of the gut. In our series, meticulously performed end ileostomy reduced the chances of stoma prolapse and further simplified management.

Even with a functioning ileostomy, episodes of functional obstruction occurred in our patients. Typically, the ileostomy output was irregular, with periods of massive output alternating with periods of no output. Paradoxically, bilious nasogastric aspirates coexisted with large ileostomy losses. There should be unequivocal evidence of mechanical obstruction before performing any further laparotomies, not least because our children were prone to prolonged paralytic ileus after any surgery, and at laparotomy multiple adhesions were always found. Further surgery can only add to them. Our experience in this series amply supports earlier studies that pointed out that repeated surgery only resulted in dense adhesions and increased morbidity.

High ileostomy washouts were effective in two of our patients. The success of this treatment in these patients might have been the result of less extensive disease or the efficacy of daily ileostomy washouts in allowing regular

\section{Key messages}

- Chronic intestinal pseudo-obstruction requires coordinated investigation by physician, surgeon, and pathologist

- Manometry and histopathological diagnosis provide prognostic information

- Decompression stomas provide treatment, allow diagnosis, and may prevent unnecessary further surgery

- Long term total parenteral nutrition may be required

decompression of the small bowel. It may be worthwhile to evaluate this procedure further to determine its efficacy.

Once a defunctioning stoma has relieved the symptoms the next inevitable question is whether the stoma can be dispensed with. In our series, four children with well functioning ileostomies had their stomas closed; however, this was unsuccessful and all developed acute obstructive symptoms and needed ileostomies to be refashioned. The cause of failure in these cases was persistent dysmotility of the bowel proximal to the stoma. An ileo-rectal Duhamel pull through procedure using the ileum proximal to the stoma proved to be the best definitive procedure in our series. It would appear logical to bypass all the affected bowel similar to the definitive management of Hirschsprung's disease; however, this might not always be possible without resecting excessive amounts of intestine. Although it may appear illogical to place a stoma in affected bowel, there may be sufficient residual motor function to allow the stoma to act but not to evacuate the bowel through the anus.

In children with extensive severe disease TPN has been the mainstay of treatment. If there are no signs of improvement in intestinal function within a few weeks, a tunnelled central venous catheter should be inserted surgically, because it is likely that the need for TPN will continue for many months. ${ }^{475051}$ Catheter blockage and/or infections are the main complications associated with long term TPN. Before 1987, seven children died while on TPN for less than one year because of TPN related complications. However, with meticulous nursing care or with "home TPN" the incidence of line infections has since been lower. $^{52}{ }^{53}$ The duration of dependence on TPN appears to be of crucial prognostic importance. There have been 10 survivors among the 13 patients requiring TPN for longer than six months. All 10 have failed repeated attempts to wean them off parenteral nutrition. The only seven children currently on full enteral nutrition required TPN for less than six months. It appears that if the disease is severe enough to require TPN for more than six months, it is likely that the child will be dependent on TPN for at least four years.

The above data suggest that with extensive severe disease only a small improvement in bowel motility with the passage of time can be 
anticipated, as has been proposed previously in some adults. ${ }^{54}$ Patients with an acquired disease, particularly of autoimmune origin, may deteriorate without specific treatment. ${ }^{16}$ One such patient with an autoimmune ganglionitis succeeded in denervating her entire gastrointestinal tract. Ultimately, there were serious vascular access problems and she underwent intestinal transplantation. She is well now some five years after transplantation.

Recent advances in enteral nutrition, such as modular feeds and continuous rate infusions, have been helpful in weaning children off TPN. ${ }^{55}$ In nine children in our series, TPN was completely avoided by the combination of dietary measures and a defunctioning stoma.

We were able to identify five poor prognostic factors: involvement of the urinary tract, early age at onset of symptoms, short small intestine, midgut malrotation, and myopathic histology. The latter three are known to be common in severe disease, ${ }^{5657}$ and thus might be expected to result in poor prognosis. The only surgical procedures that were successful were Ladd's procedure where there was a malrotation and this prevented intestinal volvulus, a defunctioning ileostomy, and ultimately an ileo-rectal Duhamel pull through, especially where the disease was confined to the terminal ileum and colon. Our observations at surgery confirmed the propensity for patients with these disorders to form dense adhesions postoperatively. From our studies, we would strongly suggest that only planned surgery for initial diagnosis and bowel decompression should be undertaken in these patients. Laparotomies for obstruction should only be performed where there are clear focal signs or mechanical obstruction has been demonstrated.

1 Schuffler MD, Keich A. Chronic idiopathic intestinal pseudo-obstruction: a surgical approach. Ann Surg 1981;192:252-6.

2 Puri P, Lake BD, Gorman F, et al. Megacystis-microcolonintestinal hypoperistalsis syndrome: a visceral myopathy. $\mathscr{f}$ Pediatr Surg 1983;18:64-8.

3 Milla P J. Gastrointestinal motility disorders in children. Pediatr Clin North Am 1988;35:311-30.

4 Kirlane J, Talwalker V, Datsur D. Megacystis-microcolonintestinal-hypoperistalsis syndrome: possible pathogenesis. $\mathcal{F}$ Pediatr Surg 1984;19:172-3.

5 Shawis RN, Rangecroft L, Pook M, Gouch DC. Functional intestinal obstruction associated with malrotation and short small bowel. $\mathcal{F}$ Pediatr Surg 1984;19:172-3

6 Devane SP, Ravelli AM, Bisset WM, Smith VV, Lake BD, Milla PJ. gastric antral dysrythmias in children with chronic intestinal pseudo-obstruction (CIIP). Gut 1992;33:147781.

7 Anuras S, Mitros FA, Milano A, Kuminsky R, Decanio R, Green JB. A familial visceral myopathy with dilatation of the entire gastrointestinal tract. Gastroenterology 1986;90: 385-90.

8 Shaw A, Shaffer H, Teja K, Kelly T, Grogan E, Brun C. A perspective for paediatric surgeons: chronic idiopathic intestinal pseudo-obstruction. 7 Paediatr Surg 1979;14: 719-27.

9 Lake BD, Puri P, Nixon HH, Claireaux AE. Hirschsprung's disease. An appraisal of histochemically demonstrable acetylcholinesterase activity in suction rectal biopsy specimen as an aid to diagnosis. Arch Pathol Lab Med 1978;102:2447 .

10 Smith VV. Intestinal neuronal density in childhood: a baseline for the objective assessment of hypo- and hyperganglionosis. Pediatr Pathol 1993;13:225-37.

11 Smith VV, Lake BD, Kamm MA, Nicholls JR. Intestinal pseudo-obstruction with deficient smooth muscle alph actin. Histopathology 1992;21:535-42.

12 Smith VV, Lake BD. Pathology of intestinal pseudoobstruction. In: Kamm MA, Lennard-Jones JE, eds. Constipation and related disorders: pathophysiology and management in adults and children. Petersfield: Wrightson, 1994:241-50.

13 Fenton TR, Harries JT, Milla PJ. Disordered intestinal motility: a rational basis for toddler's diarrhoea. Gut 1983; 24:897-903.
14 Auricchio A, Brancolini V, Casari G, et al. The locus for a novel syndromic form of neuronal intestinal pseudoobstruction maps to Xq28. Am ₹ Hum Genet 1996;58:743-

15 Smith VV, Milla PJ. Histological phenotypes of enteric mooth muscle disease causing functional intestinal obstruction in childhood. Histopathology 1997;31:112-22.

16 Smith VV, Gregson N, Foggensteiner L, Neale G, Milla PJ. Acquired intestinal aganglionosis and circulating autoantibodies without neoplasia or other neural involvement. Gastroenterology 1997;112:1366-71.

17 Berdon WE, Baker DH, Blanc W, et al. Megacystismicrocolon-intestinal hypoperistalsis syndrom: a new cause of intestinal obstruction in the newborn-report of radiologic findings in five newborn girls. Am 7 Roentgenol 1978:126:957-64.

18 Wiswell $\mathrm{T}$, Rawlings J, Wilson J, et al. Megacystismicrocolon-intestinal hypoperistalsis syndrome. Pediatrics 1979;63:805-8

19 Byrne W, Cipel L, Euler A, et al. Chronic idiopathic intestinal pseudo-obstruction syndrome in children: clinical characteristics and prognosis. F Pediatrics 1977;90:585-9.

20 Sieber WK, Girdany BR. Functional intestinal obstruction in newborn infants with morphologically normal gastrointestinal tracts. Surgery 1963;53:357-61.

21 Lan DH, Ten Eyck EA. Familial megaduodenum and megacystis. Am f Med 1961;33:911-22.

22 Faulk DL, Anuras L, Christensen J. Chronic intestinal pseudo-obstruction. Gastroenterology 1978;74:922.

23 Bindl L, Emons D, Haverkamp F, Fhanenstich H, Kowalewski S, Meier-Ruge W. Megacystis microcolon intestinal hypoperistalsis syndrom: a neuropathy? Zeitschrift fur Kinderchirurgie 1989;44:24-52.

24 Levin MD. The syndrome of chronic idiopathic intestinal pseudo-obstruction. Khirurgiya 1988;7:60-3.

25 Isaacson C, Wainwright HC, Hamilton DG, Ou Time L. Hollow visceral myopathy in black South Africans. A report of 14 cases. South African Medical fournal 1985;67:101517

26 Schuffler MD. Chronic intestinal pseudo-obstruction syndromes. Med Clin North Am 1981;65:1331-75.

27 Nonaka M, Goulet O, Arahan P, Fekete C, Ricour C, Nezelof C. Primary intestinal myopathy, a cause of chronic idiopathic intestinal pseudoobstruction syndrome (CIPS): clinicopathological studies of seven cases in children. Paediatric Pathology 1989;9:409-24.

28 Mishalany H, Olson A, Khan F, Santos A. Deficient neurogenic innervation of the myenteric plexus with normal submucous plexus involving the entire small and large bowel. $\mathcal{F}$ Pediatr Surg 1989;24:83-6.

29 Ikeda K, Goto S, Nagasaki A, Taguchi T. Hypogenesis of intestinal ganglion cells: a rare cause of intestinal obstruction simulating aganglionosis. Zeitschrift fur Kinderchirurgie 1989;43:52-3.

30 Glassman M, Spivak W, Mininberg D, Madara J. Chronic idiopathic intestinal pseudoobstruction: a commonly misdiagnosed disease in infants and children. Pediatrics 1989;83:603-8.

31 Milla PJ. Clinical features of intestinal pseudo-obstruction in children. In: Kamm MA, Lennard-Jones JE, eds. Constipation. Petersfield: Wrightson, 1994:251-8.

32 Ament ME, Vargas J. Diagnosis and management of chronic intestinal pseudo-obstruction syndromes in infancy and childhood. Arquivos de Gastroenterologia 1988;25:157-65.

33 Rohrman CA Jr, Ricci MT, Krishnamurthy S, Schuffler MD. Radiologic and histologic differentiation of neuromuscular disorders of the gastrointestinal tract: visceral myopathies, visceral neuropathies, and progressive sysmyopathies, visceral neuropathies, and progressive sys-

34 Stanghellini V, Camilleri M, Malagelada JR. Chronic idiopathic intestinal pseudo-obstruction: clinical and intestinal manometric findings. Gut 1987;28:5-12.

35 Summers RW, Anuras S, Green J. Jejunal manometry patterns in health, partial intestinal obstruction and pseudo-obstruction. Gastroenterology 1983;85:1290-300.

36 Smith VV, Milla PJ. Argyrophilia in the developing myenteric plexus. Br F Biomed Sci 1996;53:278-83.

37 Lipton AS, Knauer CM. Pseudo-obstruction of the bowel: therapeutic trial of metoclopramide. Am f Dig Dis 1977;22: 263-5.

38 Schang JC, Devroede G. Beneficial effects of nalaxone in a patient with intestinal pseudo-obstruction. Am F Gastroenterol 1985;80:407-11.

39 Laustsen J, Harling H, Fallingborg J. Treatment of chronic idiopathic intestinal pseudo-obstruction. Dig Dis Sci 1987; 32:222-3.

40 Berger SA, Keshavarzian A, DeMeo MT, Mobarhan S. Erythromycin in chronic intestinal pseudo-obstruction [letter]. F Clin Gastroenterol 1990;12:363.

41 Edwards CA, Holden A, Brown C, Read NW. Effect of cisapride on the gastrointestinal transit of a solid meal in normal subjects. Gut 1987;28:13-16.

42 Abell TL, Camilleri M, DiMagno EP, et al. Cisapride is effective in the long term treatment of gastric motor disorders. Gastroenterology 1987;92:1287.

43 Di Lorenzo C, Reddy SN, Villanueva-Meyer J, Mena I, Martin S, Hyman PE. Cisapride in children with chronic intestinal pseudoobstruction. An acute, double-blind, crossover, placebo-controlled trial. Gastroenterology 1991; 101:1564-70.

44 Vargas JH, Sachs P, Ament ME. Chronic intestinal pseudoobstruction syndrome in paediatrics: results of a national survey by members of the North American Society of Pae- 
diatric Gastroenterology and Nutrition. F Pediatr Gastroenterol Nutr 1988;7:323-32.

45 Krishnamurthy S, Heng Y, Schuffler MD. Chronic intestinal pseudo-obstruction in infants and children caused by diverse abnormalities of the myenteric plexus. Gastroenterology 1993;104:1398-408.

46 Finco C, Zaninotto G, Pittoni G, et al. Chronic idiopathic intestinal pseudo-obstruction. Minerva Chirurgica 1991;46: 747-53.

47 Bagwell CE, Filler RM, Cutz E, et al. Neonatal intestinal pseudo-obstruction. F Pediatr Surg 1984;19:732-9.

48 Anuras S, Mitros FA, Soper RT, et al. Chronic intestinal pseudo-obstruction in young children. Gastroenterology 1986;91:62-70.

49 Pitt HA, Mann LL, Berquist WE, et al. Chronic intestinal pseudo-obstruction: management with total parenteral nutrition and a venting enterostomy. Arch Surg 1985;120: 614-18.

50 Warner E, Jeejeebhoy KN. Successful management of chronic intestinal pseudo-obstruction with home parenteral nutriintestinal pseudo-obstruction with home parent

51 Kadowaki $\mathrm{H}$, Ouchi $M$, Kaga $M$, et al. Problems of trace elements and vitamins during long term total parenteral nutrition: a case report of idiopathic intestinal pseudoobstruction. $7 P E N ~ \mathcal{F}$ Parenter Enteral Nutr 1987;11:322-5

52 Bisset WM, Stapleford P, Long S, Chamberlain A, Sokel B, Milla PJ. Home parenteral nutrition in chronic intestinal failure. Arch Dis Child 1992;67:109-14.

53 Herfindal ET, Bernstein LR, Wong AF, Hogue VW, Darbinian JA. Complications of home parenteral nutrition. Clinical Pharmacy 1992;11:543-8

54 De Giorgio R, Biasco G, Brillanti S, Paparo GF, Barbara L. Reversibility of gastrointestinal motor abnormalities in chronic intestinal pseudo-obstruction. Hepatogastroenterolchronic intestinal pse
ogy 1992;39:34-8.

55 Hiyama DT. The current role of small-bowel transplantation in intestinal failure. Nutrition in Clinical Practice 1993; 8:5-11

56 Schuffler MD, Rohrmann CA, Chaffee RG, et al. Chronic intestinal pseudo-obstruction: a report of 27 cases and review of the literature. Medicine 1981;60:173-96.

57 Bestuynder R, Menget A, Denstuynder O, et al. Chronic intestinal pseudo-obstruction syndrome in infants and associated anomalies. Archives Francaises de Pediatrie 1991; 48:119-22.

\section{FETAL AND NEONATAL EDITION}

\section{Fuly issue}

The following articles-being published in the July 1999 issue of the Fetal and Neonatal edition of the Archives of Disease in Childhood - may be of general interest to paediatricians.

\section{ANNOTATION}

Recent advances in neonatology

f $M$ Rennie, $S$ A Bokhari

\section{ORIGINAL ARTICLES}

Neurodevelopmental outcome at early school age of children born to mothers with gestational diabetes

A Ornoy, $A$ Wolf, $N$ Ratzon C Greenbaum, $M$ Dulitzky

Iron nutritional status in preterm infants fed formula fortified with iron

Ian $\mathcal{F}$ Griffin, Richard $\mathcal{F}$ Cooke, Michael M Reid, Kenneth PB McCormick, facqui S Smith

Longitudinal study of behaviour disorders in low birthweight infants

$C$ F Stevenson, P Blackburn, P O D Pharoah

Safety and effectiveness of BCG vaccination in preterm babies

Sudhin Thayyil-Sudhan, Ashok Kumar, Meharban Singh, Vinod Kumar Paul, Ashok Kumar Deorari

Severe apnoeas following immunisation in premature infants

M H Slack, D Schapira

\section{CURRENT TOPIC}

Low birth weight and adult insulin resistance: the "catch-up growth" hypothesis Stefano Cianfarani, Daniela Germani, Francesco Branca 